\title{
Delayed Hypothermia as Selective Head Cooling or Whole Body Cooling Does Not Protect Brain or Body in Newborn Pig Subjected to Hypoxia-Ischemia
}

\author{
MATHIAS KARLSSON, JAMES R. TOOLEY, SAULIUS SATAS, CATHERINE E. HOBBS, ELA CHAKKARAPANI, JANET STONE, \\ HELEN PORTER, AND MARIANNE THORESEN
}

Clinical Science at South Bristol (Child Health) [M.K., J.R.T., S.S., C.E.H., E.C., J.S., H.P., MT], University of Bristol, Bristol, BS2 8EG, United Kingdom; Institutionen Sodersjukhuset [M.K.], Karolinska Institutet, Karlstad, S-652 30, Sweden; Leicester Royal Infirmary [H.P.], Leicester, LE1 5WW, United Kingdom

\begin{abstract}
The neuroprotective efficacy of hypothermia (HT) after hypoxia-ischemia (HI) falls dramatically the longer the delay in initiating HT. Knowledge is scarce regarding protective or adverse effects of HT in organs beyond the brain. In addition, the relative effectiveness of selective head cooling (SHC) and whole body cooling (WBC) has not been studied. We aimed to examine whether $24 \mathrm{~h}$ $\mathrm{HT}$, initiated $3 \mathrm{~h}$ after global HI is brain- and/or organ-protective using pathology, neurology, and biochemical markers. Fifty, $\leq 1$-dold pigs were subjected to global HI causing permanent brain injury. Animals were randomized to normothermia $(\mathrm{NT}),\left(\mathrm{T}_{\text {rectal }}\right) 39.0^{\circ} \mathrm{C}$, $\mathrm{SHC}_{\text {Trectal }} 34.5^{\circ} \mathrm{C}$, or $\mathrm{WBC}_{\text {Trectal }} 34.5^{\circ} \mathrm{C}$ for $24 \mathrm{~h}$, all followed by $48 \mathrm{~h}$ NT. There was no difference in injury to the brain or organs between groups. There was no gender difference in brain injury but females had significantly more organs injured $[2.3( \pm 1.3)$ [mean \pm SD] vs. $1.4 \pm(1.0)]$. The postinsult decline in lactate was temperature independent. However, HT animals normalized their plasma-calcium, magnesium, and potassium significantly faster than NT. Delayed SHC or WBC, initiated $3 \mathrm{~h}$ after HI, does not reduce pathology in the brain nor in organs. Delayed HT improves postinsult recovery of plasma-calcium, magnesium, and potassium. There were no differences in adverse effects across groups. (Pediatr Res 64: 74-80, 2008)
\end{abstract}

$\mathrm{H}^{\prime}$ ypothermia (HT) after hypoxia-ischemia (HI) is neuroprotective in experimental models across different species (1-3) with both short and long-term survival $(4,5)$ and after a delay between insult and treatment $(6,7)$. Recent, multicenter, randomized controlled clinical trials used two cooling methods; selective head cooling (SHC) combined with mild systemic HT to rectal temperature $\left(\mathrm{T}_{\text {rectal }}\right) 34.5^{\circ} \mathrm{C}$ (Gluckman, 2005) (8) or whole body cooling (WBC) to $\mathrm{T}_{\text {rectal }}$ $33.5^{\circ} \mathrm{C}(9,10)$. In newborn term infants with hypoxic-ischemic encephalopathy (HIE), both the methods of cooling improved neurodevelopmental outcome (11). The two larger multicenter trials of HT applied to neonates $(8,9)$ did not aim to examine organ protection after HT; however, some cardiovascular and biochemical results were reported and no differences between

Received November 6, 2007; accepted February 20, 2008.

Correspondence: Marianne Thoresen, M.D., Ph.D., Department of Clinical Science at South Bristol, University of Bristol, St Michael's Hospital, Level D, Bristol, BS2 8EG, United Kingdom; e-mail: Marianne.thoresen@bristol.ac.uk

This work was supported by The Wellcome Trust (UK), who provided the main funding, along with support from Laerdal Foundation for Acute Medicine (Norway), The Swedish Medical Research Council and Research and Public Health in Värmland.

M.K. and J.R.T. contributed equally to this study. cooled and noncooled infants were seen. In a smaller WBC trial by Eicher et al. (10) where less mature infants ( $\geq 35 \mathrm{wk}$ gestational age) were also included and the most profound cooling $\left(33.0^{\circ} \mathrm{C}\right)$ of the three trials was applied, the cooled infants needed longer inotropic support than the normothermic infants. Clotting times in the cooled infants were also abnormal more often.

Although most piglet models produce an insult largely confined to the brain (12), our piglets are subjected to global HI allowing examination of systemic effects of treatment interventions as well as effects on the brain. Previously, we have shown that this model displays the same type of brain and organ injury and cardiovascular responses seen in the asphyxiated infant (2,13-15). It has been suggested that SHC is superior to WBC, offering greater cortical protection and fewer adverse systemic effects. Yet, the two modes of cooling have not previously been compared in the same trial, clinically or experimentally. We aimed to examine whether $24 \mathrm{~h}$ of HT, initiated $3 \mathrm{~h}$ after global $\mathrm{HI}$ is neuro- or organ-protective and whether any differences exist between SHC and WBC in organ or brain pathology or biochemical markers.

\section{METHODS}

Protocols were approved by the University of Bristol Ethical Review Panel and carried out in accordance with British Home Office guidelines.

Preparation. Crossbred Landrace-Large White, newborn pigs were kept in a calm, heated environment and bottle-fed pig formula (Faramate; Volac Feeds, Royston, UK) ad libitum. The 50 pigs included in this study showed a nonsignificant $(p=0.061)$ difference in proportion of males/females between the groups [normothermia (NT) 11/5, WBC 10/7, and SHC 5/12]. The median [interquartile range (IQR)] age was $20 \mathrm{~h}(16.5-24)$ and weight $1570 \mathrm{~g}(1380-1750)$.

Anesthesia was induced in a closed perspex box, with halothane (3\%), $\mathrm{N}_{2} \mathrm{O}(67 \%)$, and $\mathrm{O}_{2}(30 \%)$, followed by endotracheal intubation and mechanical ventilation with maintenance anesthesia. Antibiotics were administered 12 hourly throughout the study period. Pigs with a mean arterial blood pressure (MABP) less than $40 \mathrm{~mm} \mathrm{Hg}$ were treated with two boluses of saline followed by inotropic drugs if necessary.

Abbreviations: AUC, area under curve; HI, hypoxia-ischemia; HIE, hypoxic ischemic encephalopathy; HT, hypothermia; IQR, interquartile range; MABP, mean arterial blood pressure; MOD, multiorgan dysfunction; NT, normothermia; SHC, selective head cooling; $\mathbf{T}_{\text {rectal }}$, rectal temperature; UVC, umbilical vein catheter; WBC, whole body cooling 
Body temperature was recorded using a rectal probe inserted $6 \mathrm{~cm}$ from the anal margin. Brain temperature was measured with calibrated microthermocouples (Physitemp Instruments Ltd, Clifton, NJ) in the superficial cortex and at $2.2 \mathrm{~cm}$ from the brain surface, at the level of the basal ganglia. Temperatures were recorded digitally every minute. Single-channel biparietal electroencephalography (EEG) (Medilog) and amplitude integrated EEG (aEEG) (Olympic 6000) were applied. Values for temperature, MABP, heart rate, oxygen saturation, and aEEG were recorded continuously. Biochemical and hematological variables including creatinine, sodium $(\mathrm{Na})$, potassium $(\mathrm{K})$, chloride $(\mathrm{Cl})$, magnesium $(\mathrm{Mg})$, calcium (not albumin corrected) $(\mathrm{Ca})$, alanine aminotransferase, aspartate aminotransferase, lactate dehydrogenase, gammaglutamyl transferase, bilirubin, albumin, total protein, white blood cell count, red blood cell count, hemoglobin $(\mathrm{Hb})$, hematocrit, platelet count, glucose, lactate, and blood gases were recorded before, during and postinsult at predetermined time points.

The HI insult. The HI model with modifications has previously been described $(2,13)$. Briefly, hypoxia was induced and the fraction inspired oxygen maintained at $\sim 5-6 \%$, resulting in suppressed and low amplitudeEEG $<7 \mu \mathrm{V}$. This degree of HI has been shown to induce permanent brain injury in newborn pigs (13). Forty-five minutes, HI was followed by reoxygenation with $30 \% \mathrm{O}_{2}$ until the transcutaneous oxygen saturation was $\geq 92 \%$, which usually occurred within 5 min.

After the HI insult. Inhalation anesthesia continued until the onset of HT ( $3 \mathrm{~h}$ after the end of $\mathrm{HI}$ ) when it was replaced by i.v. anesthesia of propofol and fentanyl for $24 \mathrm{~h}$. After anesthesia, intramuscular injections of buprenorphine $(10-20 \mu \mathrm{g} / \mathrm{kg}$ every $12 \mathrm{~h})$ were given for analgesia. Pigs were extubated when spontaneous breathing was adequate. Posthypoxic clinical or electrical seizures were treated as required.

Cooling procedures. Three hours after HI, pigs were randomized to one of three strategies: NT $\left(\mathrm{T}_{\text {rectal }} 39.0^{\circ} \mathrm{C}\right)$ or HT $\left(\mathrm{T}_{\text {rectal }} 34.5^{\circ} \mathrm{C}\right)$ using a cooling blanket (Tecotherm TS 200 Tec, Com Halle Germany) (WBC), or a cooling cap (Olympic Medical, Seattle, US) (SHC). Temperatures were maintained for $24 \mathrm{~h}$. Rewarming at $0.8^{\circ} \mathrm{C} / \mathrm{h}$ to $39^{\circ} \mathrm{C}$ was started by removing the cooling cap or blanket.

Neurology assessment. An 11-item scoring system $(2,13)$ was applied before $\mathrm{HI}$ and at 27, 33, 48, and $72 \mathrm{~h}$ after the insult. Seventy-two hours post-HI animals were reanesthetized and intubated. Under deep anesthesia, brains were perfused through the common carotid arteries with $4 \%$ formaldehyde. A full autopsy was performed immediately with description of macroscopic pathology. All internal organs were immersion fixed in $4 \%$ formaldehyde. Placement of the umbilical venous and arterial catheters was documented. A perinatal pathologist (H.P.) carried out a second, detailed autopsy, examined the organs and scored them with zero for no lesions, or one for presence of histologic lesions (15). Ten coronal sections were examined from each brain, sampled at regular, $0.5 \mathrm{~cm}$ intervals. Seven regions of the brain were analyzed for the average brain pathology score as previously described $(2,13)$. These were, cortical gray matter, white matter, basal ganglia, hippocampus, thalamus, cerebellum, and brainstem.
Two animals failed to recover after HI with persistent isoelectric EEG and documented brain death and were thus excluded from the study.

Survival. Six pigs died prematurely because of cardiovascular compromise caused by HI, two in the NT group (at 33 and $56 \mathrm{~h}$ ), two in SHC group (at 34 and $53 \mathrm{~h}$ ), and two in WBC group (at 48 and $68 \mathrm{~h}$ ). All six were included in the analyses as they survived beyond the rewarming period $(33 \mathrm{~h})$.

Data analysis. A linear regression analysis was performed with number of damaged organs or average brain pathology as the dependent variable. A significance value of 0.05 was used when allowing independent factors (Tables 1 and 2) to enter the regression. Normally distributed continuous variables at baseline were compared at the selected time points after HI by paired t test. Data that were not normally distributed were analyzed with nonparametric statistics: Wilcoxon matched pairs test with Bonferroni's correction for multiple comparisons, Mann-Whitney U test, and Kruskal Wallis rank test. Nominal data were evaluated using $\chi^{2}$ test or Fisher's exact test. Areas under the curve (AUC) for continuous data during the cooling period were calculated with the trapezium rule.

\section{RESULTS}

There was no difference in baseline variables or in the severity of HI across the three groups (Table 3). During cooling, rectal and brain temperature AUCs (Fig. 1) were significantly lower in the SHC and WBC groups compared with the NT group $(p<0.001)$. There was no difference in $\mathrm{T}_{\text {rectal }}$ between SHC and WBC groups during the $24 \mathrm{~h}$ hypothermic period. Deep and superficial brain temperatures were lower in the SHC group than the WBC group (Fig. 1). $\mathrm{T}_{\text {rectal }}$ did not differ during the remainder of the experimental period (Fig. 1). AUC for heart rate in SHC $(n=17)$ and WBC $(n=$ 17) groups were significantly lower than the NT group $(n=$ 16) $(p=0.001 v s . p<0.001)$. AUC for MABP, arterial $\mathrm{pH}$, base excess, glucose, $\mathrm{pCO}_{2}, \mathrm{pO}_{2}$, and $\mathrm{HCO}_{3}$ did not differ across groups during the insult, cooling period nor thereafter. Mean $( \pm$ SD) plasma lactate rose to $19.5 \mathrm{mM}( \pm 3.7)$ by the end of the insult. The recovery time to normal values after reoxygenation was similar across the groups (Fig. 2) with normalization in lactate at $3 \mathrm{~h}$ postinsult compared with baseline ( $p=0.417)$.

Brain. There was no difference in average brain pathology score across the three groups. Median (IQR) for average brain

Table 1. Regression model for organ pathology

\begin{tabular}{|c|c|c|c|c|c|c|}
\hline \multirow{2}{*}{$\begin{array}{l}\text { Dependant variable } \\
\text { Independent variables }\end{array}$} & \multicolumn{6}{|c|}{ Average brain pathology score (range $0.0-4.0, R=0.49, R^{2}=0.24$ ) } \\
\hline & $\mathrm{B}$ & SE & $\mathrm{t}$ & Sig & CI lower & CI upper \\
\hline Constant & 25.42 & 9.54 & 2.67 & 0.01 & 6.24 & 44.6 \\
\hline $\mathrm{pH}$ end of insult & -3.45 & 1.34 & -2.58 & 0.01 & -6.15 & -0.76 \\
\hline Duration of seizures & 0.004 & 0.002 & 2.09 & 0.04 & 0.00 & 0.01 \\
\hline
\end{tabular}

Independent variables with a relationship to the dependent variables; from linear stepwise regression model. Excluded independent were average HR and MABP during HI, age, $\mathrm{pH}$ at end of insult, treatment group, duration of dopamine infusion and seizures and duration of LA-EEG during HI.

Table 2. Regression model for brain pathology

\begin{tabular}{lrrrrr}
\hline \multirow{2}{*}{ Dependant variable } & \multicolumn{5}{c}{ No. organs with histological lesions (range 0-4, $R=0.58, R^{2}=0.33$ ) } \\
\cline { 2 - 5 } Independent variables & \multicolumn{1}{c}{$\mathrm{B}$} & $\mathrm{SE}$ & $\mathrm{t}$ & $\mathrm{S}$ Sig & \multicolumn{1}{c}{ CI lower } \\
\hline Constant & -38.64 & 15.23 & -2.54 & 0.15 & -69.30 \\
Sex & 0.99 & 0.29 & 3.49 & 0.001 & 0.42 \\
Lactate 3 h postinsult & 0.33 & 0.12 & 2.81 & 0.007 & 0.09 \\
pH 3 h postinsult & 5.12 & 2.04 & 2.51 & 0.016 & 1.57 \\
\hline
\end{tabular}

Independent variables with a relationship to the dependent variables; from linear stepwise regression model. Excluded independent were average HR and MABP during HI, age, gender, treatment group, $\mathrm{pH}$ and lactate during and $3 \mathrm{~h}$ after HI, duration of dopamine infusion and duration of LA-EEG during HI. 


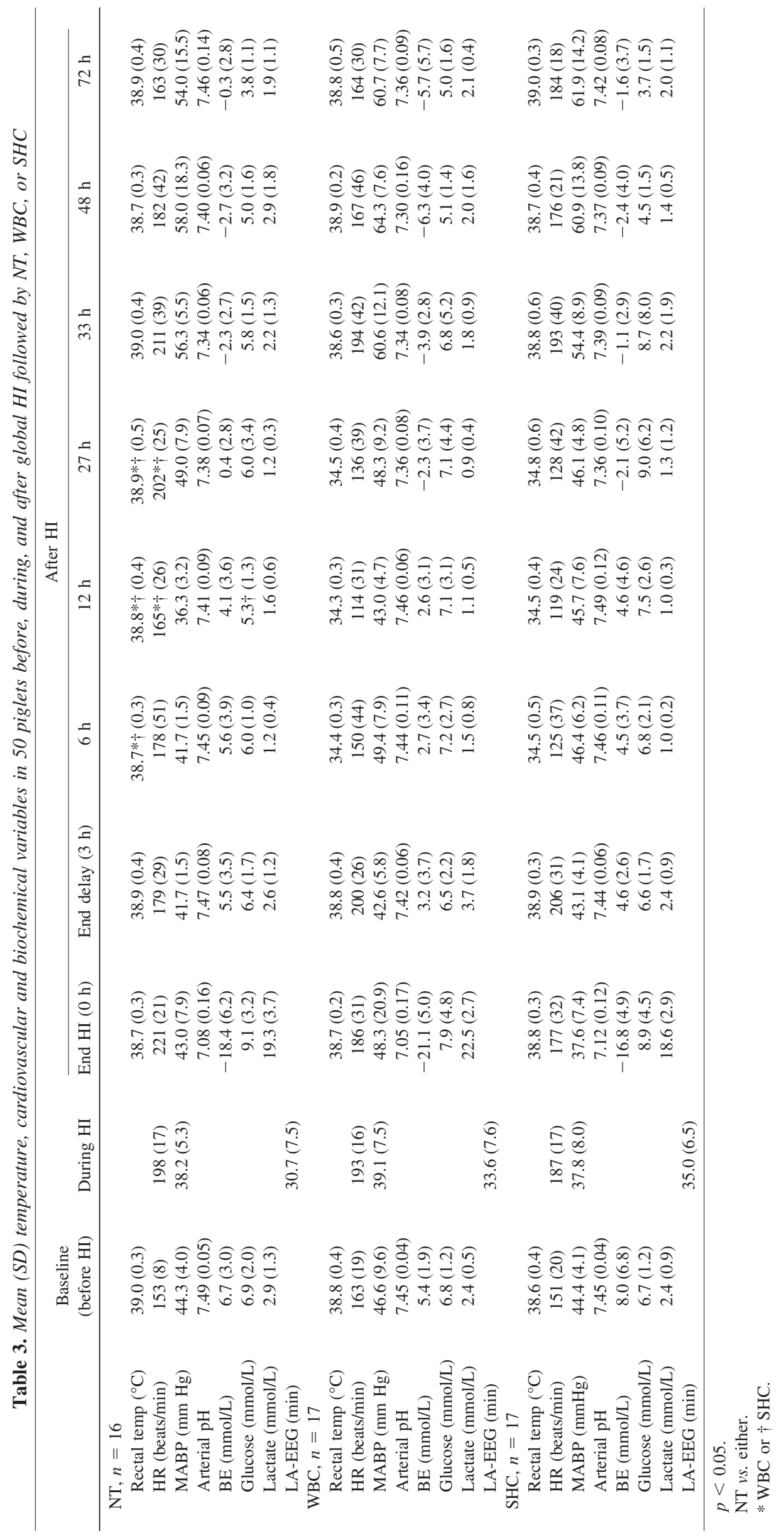



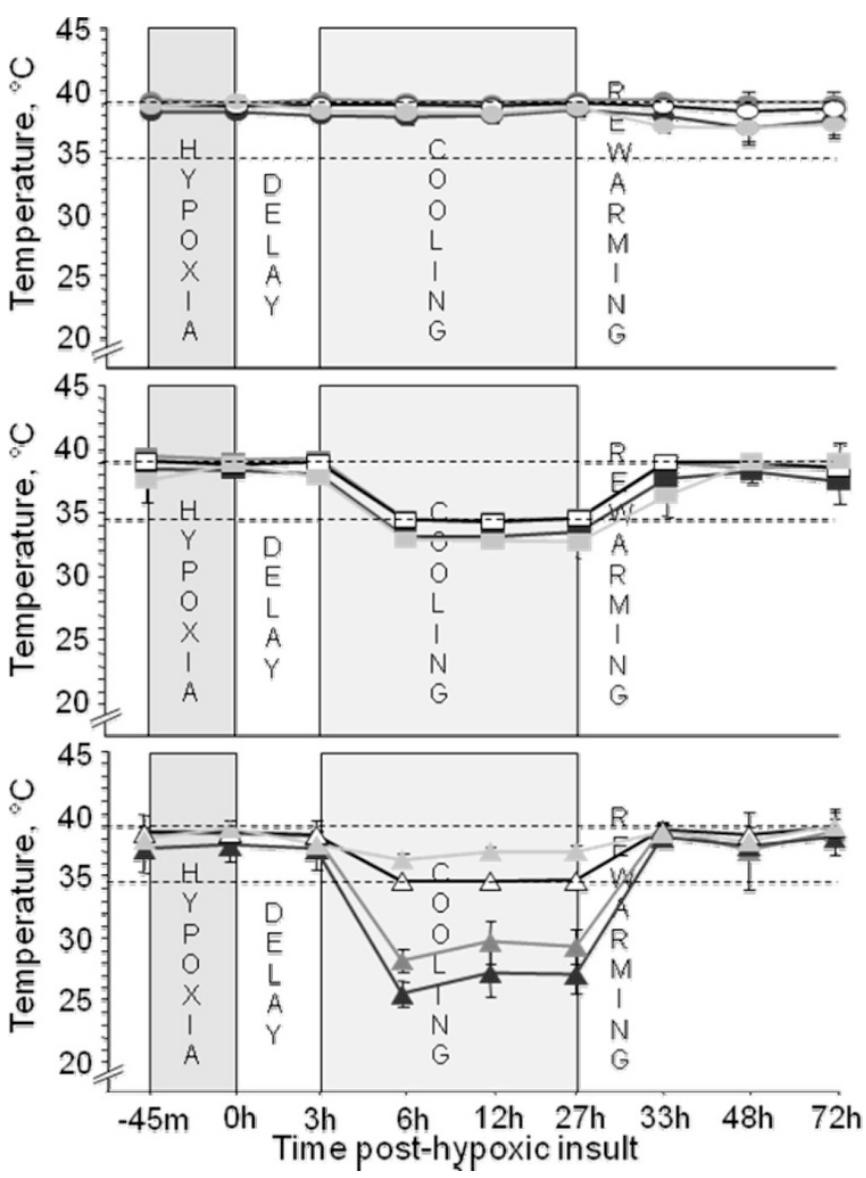

Figure 1. $(A-C)$ Rectal and brain temperatures. Mean $\pm 95 \%$ confidence interval $(\mathrm{CI})$ for A: normothermia (NT) and brain (deep $(\bigcirc)$ and superficial $(\bigcirc)$ ), rectal $(\bigcirc)$ and skin $(\bigcirc)$, B: whole body cooling (WBC) and brain (deep ( $\square$ ) and superficial $(\square)$ ), rectal $(\square)$ and skin $(\square)$ and C: selective head cooling (SHC) for brain (deep $(\triangle)$ and superficial $(\mathbf{\Delta})$ ), rectal $(\triangle)$ and skin $(\triangle)$ temperatures $\left({ }^{\circ} \mathrm{C}\right)$ before and $72 \mathrm{~h}$ after global HI followed by NT (a) WBC (b) or SHC (c).

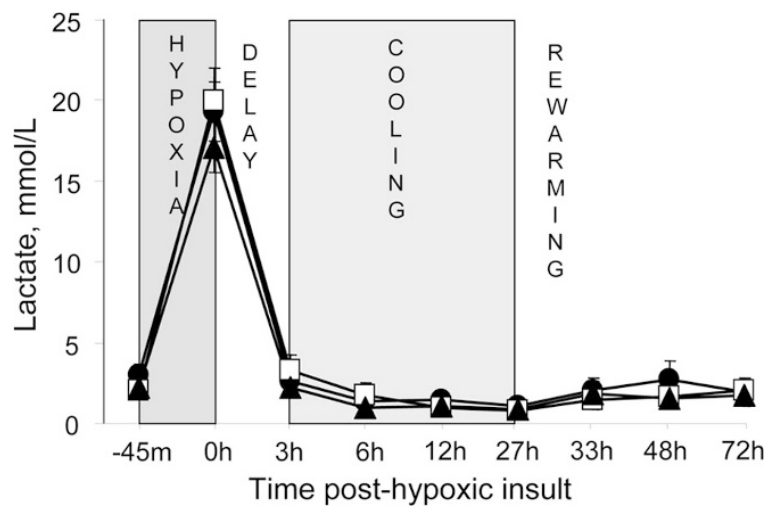

Figure 2. Blood lactate. Mean $\pm 95 \% \mathrm{CI}$ for blood lactate ( $\mathrm{mmol} / \mathrm{L})$ before and $72 \mathrm{~h}$ after global HI followed by NT $(\bullet), \operatorname{WBC}(\square)$ or SHC $(\boldsymbol{\Delta})$.

pathology score was $0.43(0.29-2.66)$ after NT, $0.86(0.25-$ $2.21)$ after SHC, and $0.50(0.29-1.00)$ after WBC. The 11item neurology score $48 \mathrm{~h}$ after $\mathrm{HI}$ did not differ across the groups. Average brain pathology and neurology correlated strongly at this time point $(r=0.5, p<0.001)$. There was no significant difference in the distribution of brain injury across the groups.
Pooling the data for regression analysis demonstrated a significant relationship between average brain pathology score and the independent variables arterial $\mathrm{pH}$ at end of insult and duration of seizures (Table 1).

Posthypoxic seizures developed in 27 animals (NT, $n=7$; SHC, $n=11$; and WBC, $n=9$ ) with no difference in the number of seizures $(p=0.480)$ or total duration of seizures between groups. The median (IQR) duration of seizures in these 27 animals that seized was $90 \mathrm{~min}(20-279)$ after NT, 56 min (20-80) after SHC, and 100 min (64-158) after WBC $(p=0.164)$. The types of brain injury seen in this model has previously been published $(13,16)$.

Organ pathology. Significantly, fewer damaged organs were observed in males than females (Mean $( \pm$ SD) $1.4( \pm 1.0)$ vs. 2.3 ( \pm 1.1$), p=0.004)$ (Table 2 and Fig. 3). Histologic pictures of typical pathologic findings are shown in Figures $4 A-F$. There was a significant relationship between the three independent variables; arterial $\mathrm{pH}$, lactate at $3 \mathrm{~h}$ after the insult (immediately before delayed cooling started), gender and the number of organs with pathologic lesions.

Liver. The most frequently damaged organ was the liver $(n=29)$ (Table 4). No difference in the prevalence of liver pathology was seen across the groups $(p=0.985)$. The pathologic findings were: Necrosis $(n=18)$ (Fig. $4 A)$, thrombus in hepatic vein $(n=12)$ (Fig. $4 B)$, subcapsular hematoma

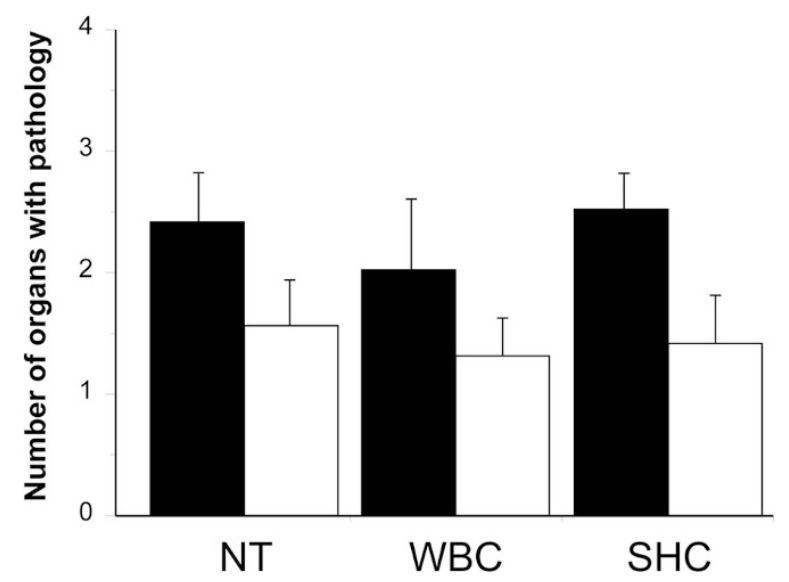

Figure 3. Organ pathology. Number of organs with pathology in newborn pigs randomized to NT, SHC, or WBC after global HI presented split for gender $($ female $=$ black, male $=$ white $)$.

Table 4. Organ pathology

\begin{tabular}{lcccc}
\hline $\begin{array}{c}\text { Organ } \\
\text { pathology }\end{array}$ & $\begin{array}{c}\text { NT } \\
(n=16)\end{array}$ & $\begin{array}{c}\text { WBC } \\
(n=17)\end{array}$ & $\begin{array}{c}\text { SHC } \\
(n=17)\end{array}$ & $\begin{array}{c}\text { Total } \\
(n=50)\end{array}$ \\
\hline Heart & $5(31)$ & $6(35)$ & $8(47)$ & $19(38)$ \\
Lung & $8(50)$ & $5(29)$ & $10(59)$ & $23(46)$ \\
Liver & $9(56)$ & $10(59)$ & $10(59)$ & $29(58)$ \\
Kidney & $7(44)$ & $6(35)$ & $8(47)$ & $21(42)$ \\
Pancreas & 0 & 0 & 0 & 0 \\
Spleen & 0 & 0 & $1(6)$ & $1(2)$ \\
Intestines & 0 & 0 & 0 & 0 \\
Adrenals & 0 & 0 & 0 & 0 \\
Total & 29 & 27 & 37 & \\
MOD & $10(63)$ & $6(35)$ & $13(76)$ & $29(58)$ \\
\hline
\end{tabular}

Number of organs with pathology (\%) at $72 \mathrm{~h}$ after global HI followed by NT, WBC or SHC. MOD is defined as two or more organs injured. 


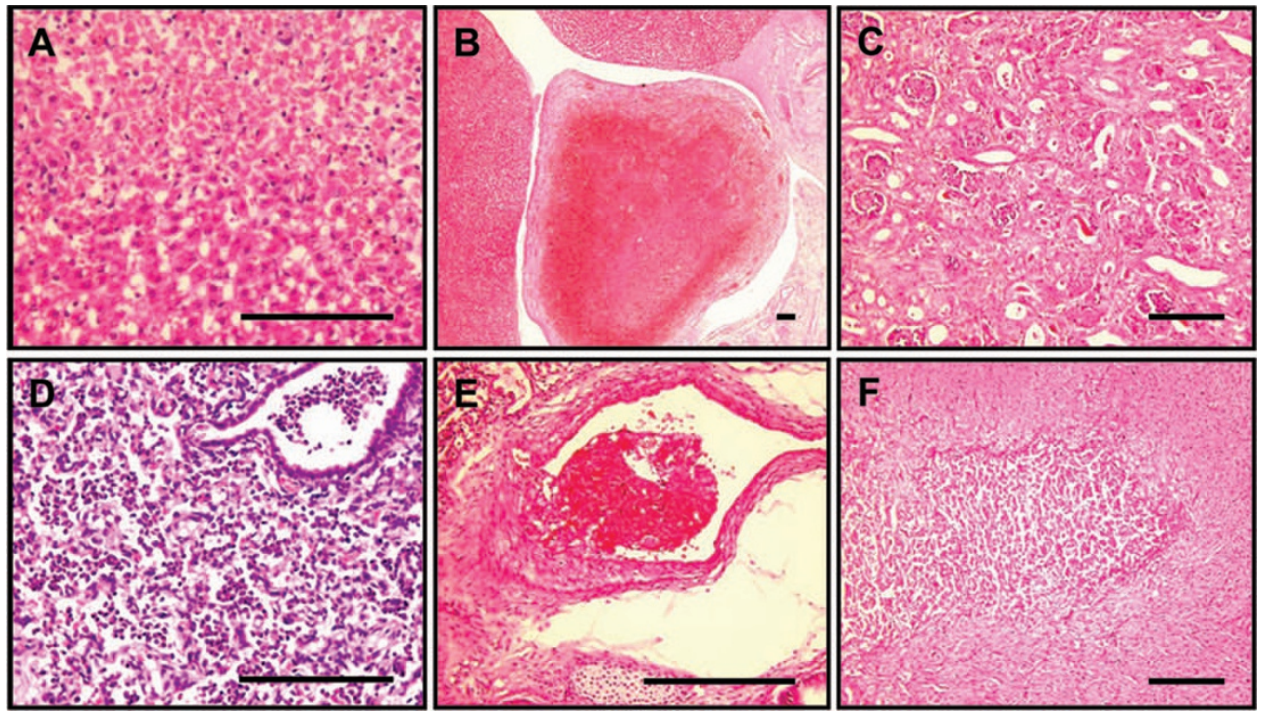

Figure 4. $(A-F)$ Organ histology. Selection of histologic lesions seen after global HI. Liver tissue with necrotic cells $(A$, magnification $\times 400$ ) and thrombus in hepatic vein $(B, \times 50)$. Kidney necrosis $(C$, $\times 200)$, lung tissue with pneumonia $(D$, $\times 400)$ and thrombus in large pulmonary artery $(E, \times 400)$ and myocardial necrosis $(F, \times 200)$. Scale bar $=200 \mu \mathrm{m}$.

$(n=2)$ or congestion $(n=1)$, and small hemorrhagic foci $(n=2)$. Areas of neutrophil infiltration in the hepatic vein vessel wall were seen in five livers. Infiltration cooccurred with bacteria in two cases. Subcapsular injury was the sole liver pathology in two cases, whereas multiple types of injury were found in 11 livers.

Location of the tip of the umbilical vein catheter (UVC) was recorded at autopsy in 29 animals. The tip of the UVC was found advanced into the liver in 19 pigs and outside the liver in 10. No relation between UVC location and liver injury was seen $(p=0.187)$.

Liver enzymes, blood lactate, and severity of insult did not differ between animals that did and did not develop liver injury.

Kidneys. Kidney lesions were seen in 21 pigs across the three groups $(p=0.774)$ (Table 4$)$. The pathologic findings were: Necrosis $(n=7)$ (Fig. $4 C)$, dilatation of tubules $(n=6)$, dilatation of collecting duct $(n=4)$, interstitial hemorrhage $(n=2)$, hydronephrosis $(n=1)$, scarred segment in cortex $(n=2)$, areas of neutrophil infiltration $(n=2)$, thrombus in small vessels $(n=5)$, and small cysts $(n=1)$. Loss of tubules and signs of fibrosis were seen in one piglet. More than one type of kidney pathology was seen in seven animals. No clinically significant differences in hematology and biochemistry, including peak creatinine were seen between animals with or without kidney damage.

Lungs and heart. Twenty-three pigs developed pulmonary lesions (Table 4). Pneumonia was seen in 18 pigs (Fig. 4D), pulmonary artery thrombus in five (one in a large artery and four in small arteries) (Fig. 4E), intraalveolar hemorrhage in two pigs, and edema in one. Pneumonia cooccurred with other lesions in three pigs. No parameters including $\mathrm{pO}_{2}$ and $\mathrm{pCO}_{2}$ were significantly affected by pathologic findings at any time point including the duration or need of ventilation $(p=0.134)$.

Cardiac injury occurred in 19 pigs. Types of injury were necrotic lesions in 18 (Fig. 4F) and a thrombus in an intracardiac vessel in one piglet. Frequency of cardiac and pulmonary injuries did not differ across groups $(p=0.621$ and $p=$ 0.221 , respectively).
Spleen, pancreas, intestines, and adrenals. Extensive necrosis in the spleen occurred in one pig. No other pathologic findings were seen in the spleen, pancreas, intestines, and adrenals.

Biochemistry. At the end of $\mathrm{HI}$, plasma-Ca, $\mathrm{Mg}$, and $\mathrm{K}$ had risen (Figs. $5 A-C$ ). This was followed by a decline $3 \mathrm{~h}$ postinsult, after which, cooling began. After $3 \mathrm{~h}$ of HT by either method, plasma-Ca had recovered significantly compared with NT. During the cooling period (3-27 h after HI), mean $( \pm \mathrm{SD})$ AUC for plasma-Ca was significantly lower in the NT group $[2.53( \pm 0.23)]$ compared with SHC $[2.72$ $( \pm 0.17)]$ and WBC $[2.75( \pm 0.15)]$ groups (Fig. $5 A)$. The same trend was seen for plasma-Mg. AUC for plasma-Mg was 0.63 $( \pm 0.07)$ after NT, $0.69( \pm 0.07)$ after SHC, and $0.68( \pm 0.08)$ after WBC. The difference was significant for the SHC and WBC groups compared with NT at $6 \mathrm{~h}(p=0.003$ and 0.016$)$ and $9 \mathrm{~h}(p=0.005$ and 0.014$)$ postinsult, and between SHC and NT groups $9 \mathrm{~h}$ postinsult $(p=0.013)$.

The opposite pattern was seen for plasma-K where lower levels were detected in the WBC $(p=0.002)$ and SHC $(p=$ 0.017 ) groups compared with NT, $6 \mathrm{~h}$ postinsult ( $3 \mathrm{~h}$ into delayed cooling). No differences were seen in $\mathrm{Cl}$ and $\mathrm{Na}$ across groups.

During cooling, AUC of plasma-creatinine was significantly elevated in the NT group compared with the SHC ( $p=$ 0.007 ) group. A significant difference in plasma-creatinine between the NT and the WBC group was seen at $9 \mathrm{~h}$ into cooling $(p=0.000)$. No other differences in hematology, including platelet count, or biochemistry were seen across groups.

Drug treatment. Thirty-one animals required inotropic drugs after HI to maintain MABP above $40 \mathrm{~mm} \mathrm{Hg}$. There was no significant difference between the groups in required duration of inotropic support ( $p=0.385$ ).

Thirteen animals received phenobarbital treatment for seizures documented on aEEG/EEG, four in the NT and WBC groups and five in the SHC group with no significant difference in the numbers of doses received. Four animals required a second or third line drug (lidocaine and/or midazolam) to control seizures. 

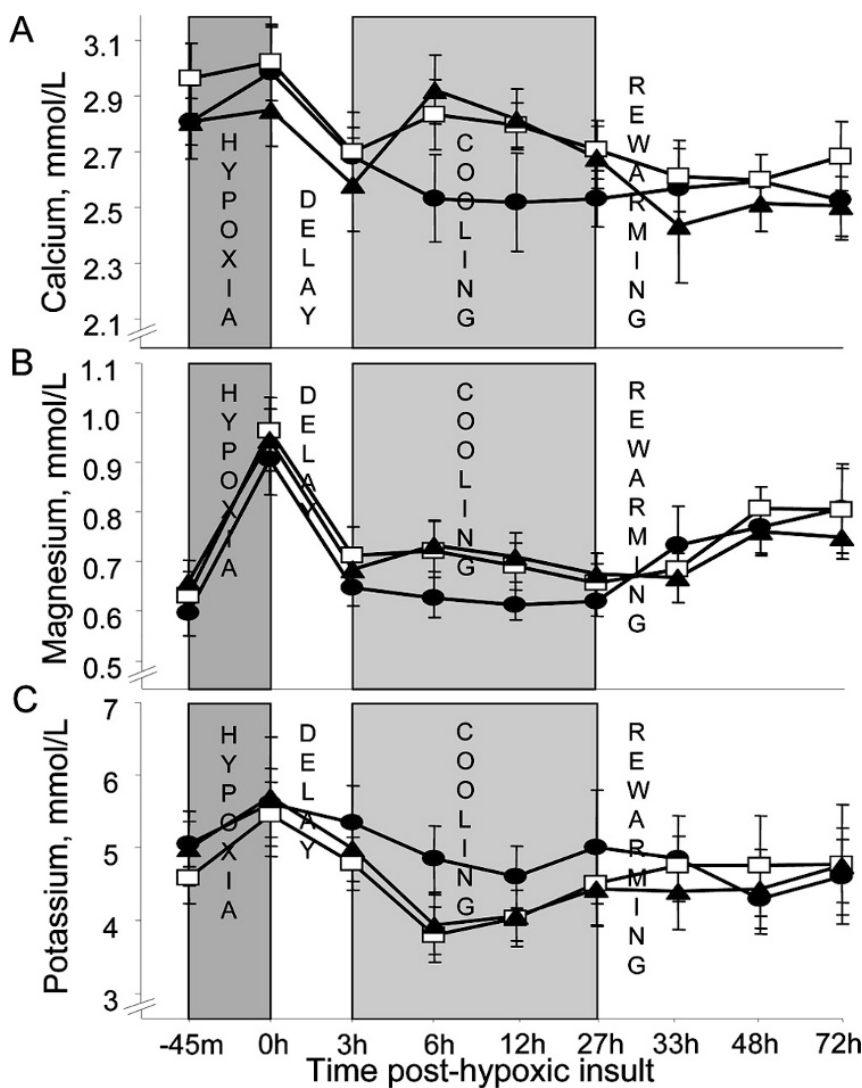

Figure 5. $(A-C)$. Plasma-Ca, $\mathrm{Mg}$, and $\mathrm{K}$. Mean $\pm 95 \% \mathrm{CI}$ for plasma $\mathrm{Ca}(A)$, $\mathrm{Mg}(B)$, and $\mathrm{K}(C)$ before and $72 \mathrm{~h}$ after global $\mathrm{HI}$ followed by NT (-), WBC $(\square)$, or SHC $(\mathbf{\Delta})$.

\section{DISCUSSION}

This is the first time the two commonly used modes of cooling have been compared in the same randomized study. The main finding of this study is that delayed HT was neither neuro- nor organ-protective, nor did either mode of cooling produce more adverse effects than NT. We found no difference between the two methods in any of the biochemical or histopathological variables investigated.

In studies on fetal sheep (6) and in clinical trials $(8,9)$ a significant effect was seen with a $5.5 \mathrm{~h}$ delay in HT treatment. Because the degree of injury in our study was relatively mild to start with, we had hypothesized that we would detect a protective effect if present as HT is thought to be more effective in milder injury (8). Previously, we found that $24 \mathrm{~h}$ HT, when started immediately, gave significant neuroprotection. If HT is applied with a delay, $24 \mathrm{~h}$ may be insufficient for this species, as is the case in fetal sheep (personal communication, Alistair Gunn).

There is no valid noninvasive measurement method for cerebral blood flow (CBF) that is suitable for a survival model that wakes up, thus we cannot monitor CBF changes in response to the insult or temperature changes. We have previously shown that Doppler flow velocity measurements, do not correspond to electromagnetic $\mathrm{CBF}$ in the newborn pig (17).

The reduction in temperature in the present study is $11.5 \%$ compared with $6.8-10.8 \%$ in the clinical HT trials. This greater depth of cooling did not cause any serious adverse effects. This is both encouraging for HT as standard care from a safety perspective and in accordance with the literature, where adverse effects were not reported above $34^{\circ} \mathrm{C}$ core temperature (18).

To our knowledge, no studies of global $\mathrm{HI}$ in newborn mammals have shown any beneficial effects of HT on organs other than the brain $(14,15,19)$. There is, however, some evidence of the positive effects of HT on organ pathology in older animals $(20,21)$. One explanation why the NT and HT groups did not differ in incidence of liver injuries in our study is that the systemic HT was mild compared with the studies discussed above.

Pneumonia was the most common lung injury, and is probably iatrogenic and related to the duration of artificial ventilation (22). Necrotizing enterocolitis can be induced by experimental HT in newborn pigs (23); however, no gut pathology was seen in the present study. This could be explained by careful introduction of oral feed as we have previously found necrotizing enterocolitis and distended abdomen with another feeding regimes $(14,24)$.

A relationship between gender and numbers of organs with lesions was seen with males suffering fewer damaged organs. This finding is in contrast to the gender distribution of multiorgan dysfunction (MOD) (25) in adults. This is the first study to show gender differences in MOD after HI in the neonatal period. It is known that organ blood flow is redistributed during $\mathrm{HI}$ in animal models. Blood flow to the lungs, liver, and kidneys decreases with redistribution to the brain, heart, and adrenals (26). One could speculate that the higher incidence of MOD in females reflects a more functional redistribution of organ blood flow and could explain the previously reported gender difference which protects females from neurologic damage in the neonatal period (27). In our NT group, the prevalence of MOD was 5/5 in the females and 6/11 in the males. Mean brain pathology score $( \pm \mathrm{SD})$ was $1.57( \pm 1.62)$ in males compared with $0.33( \pm 0.19)$ in females $(p=0.078)$. This finding is interesting and gender and organ damage should be taken into consideration in future studies of neuroprotection in the neonatal period.

Significant clinical differences in plasma-electrolytes were present during the cooling period (Figs. $5 A-C$ ). Influx of calcium into cells is a common trigger of ischemic brain cell death. Newborn infants with HIE and poor outcome have been shown to have a larger drop in serum- $\mathrm{Ca}^{2+}$ compared with infants who fully recover after HIE (28). It has also been shown in rat cortical brain slices that the rate of $\mathrm{Ca}$ influx during ischemia is reduced by low temperature (29). We speculate that the rise in $\mathrm{Ca}$ in the cooled groups in our study is due to HT-induced inhibition of cellular $\mathrm{Ca}$ influx in affected organs.

Magnesium is known to bind to $N$-methyl-D-aspartate channels and thereby block $\mathrm{Ca}$ influx leading to cell death (30). Low serum-Mg levels have been seen in cord blood of newborn infants with moderate and severe HIE (31). Next to $\mathrm{K}, \mathrm{Mg}$ is the most dominant intracellular ion and is highly affected by $\mathrm{pH}$. Even if $\mathrm{Mg}$ does not bind to proteins to the same degree as $\mathrm{Ca}$ does to albumin, protein concentrations do have an impact on plasma-Mg. In our material, no correlation was evident between $\mathrm{Mg}$ and $\mathrm{pH}$ and the albumin and protein concentrations did not differ between 
the groups. This supports our speculation that HT treatment in some way mobilizes $\mathrm{Mg}$ from the bone structure leading to greater availability of $\mathrm{Mg}$ to bind to $N$-methyl-Daspartate channels.

The biochemical pattern seen during the cooling period in our study could be a reflection of less compromise of cellular integrity during HT compared with NT. The delay before initiating cooling and/or the brevity of the HT treatment could explain why no histopathological or biochemical differences were seen across the groups.

No difference in the incidence of hypocalcaemia between HT and NT infants in the two cooling trials was seen $(8,9)$. However, the time points were too few and far between for electrolyte changes to be studied.

Reduced tissue perfusion during HT may be more profound during WBC with a lower temperature in the skin. We did not see any differences in the levels of plasma lactate (Fig. 2) between the groups. Hence, we have no evidence of diminished peripheral perfusion during either cooling method. Deranged clotting and increased bleeding tendency are well known complications of severe HT (18). Clotting was not examined in this study; however, in a previous study by Ferguson et al. (Early Hum Dev 2006 82:613) we examined APTT at $29^{\circ} \mathrm{C}$ and $39^{\circ} \mathrm{C}$ and found an increase of $15 \%$ during HT with values still within the normal range.

In conclusion, the systemic effects seen in the present study are similar to those seen in term, newborn infants with moderate to severe neonatal encephalopathy, who have been treated with HT-by either WBC or SHC $(8,9)$.

Twenty-four hours of mild HT using SHC or WBC, induced $3 \mathrm{~h}$ after a $45 \mathrm{~min}$ global hypoxic-ischemic insult, had no beneficial effects on organ or brain pathology. However, a biochemical pattern indicating less cellular death in the HT groups was seen. It has been suggested that HT would increase acidosis and that SHC would give fewer systemic adverse effects than WBC. In this study, we did not find any difference in the clearance of lactate after the insult whether treated with WBC, SHC, or NT. It was only the severity of the insult that influenced the lactate levels. There is conflicting evidence regarding gender difference in the susceptibility to HI. Gender seems to have an impact on organ pathology in our newborn pig model of global HI.

Acknowledgments. The authors thank the following companies for lending us equipment used in this study; Olympic Medical (CoolCare cooling system), SLE (neonatal ventilator), Radiometer (blood gas machine and co-oximeter) and Datex-Ohmeda (Giraffe incubator).

\section{REFERENCES}

1. Thoresen M, Penrice J, Lorek A, Cady EB, Wylezinska M, Kirkbride V, Cooper CE, Brown GC, Edwards AD, Wyatt JS, Reynolds EO 1995 Mild hypothermia after severe transient hypoxia-ischemia ameliorates delayed cerebral energy failure in the newborn piglet. Pediatr Res 37:667-670

2. Tooley JR, Satas S, Porter H, Silver IA, Thoresen M 2003 Head cooling with mild systemic hypothermia in anesthetized piglets is neuroprotective. Ann Neurol 53:65-72

3. Gunn AJ, Gunn TR, de Haan HH, Williams CE, Gluckman PD 1997 Dramatic neuronal rescue with prolonged selective head cooling after ischemia in fetal lambs. J Clin Invest 99:248-256
4. Bona E, Hagberg H, Loberg EM, Bagenholm R, Thoresen M 1998 Protective effects of moderate hypothermia after neonatal hypoxia-ischemia: short- and long-term outcome. Pediatr Res 43:738-745

5. Hobbs C, Thoresen M, Tucker A, Aquilina K, Chakkarapani E, Dingley J 2008 Xenon and hypothermia combine additively, offering long-term functional and histopathological neuroprotection after neonatal hypoxia/ischemia. Stroke 39:1307-1313

6. Gunn AJ 2000 Cerebral hypothermia for prevention of brain injury following perinatal asphyxia. Curr Opin Pediatr 12:111-115

7. Taylor DL, Mehmet H, Cady EB, Edwards AD 2002 Improved neuroprotection with hypothermia delayed by 6 hours following cerebral hypoxia-ischemia in the 14-dayold rat. Pediatr Res 51:13-19

8. Gluckman PD, Wyatt JS, Azzopardi D, Ballard R, Edwards AD, Ferriero DM, Polin RA, Robertson CM, Thoresen M, Whitelaw A, Gunn AJ 2005 Selective head cooling with mild systemic hypothermia after neonatal encephalopathy: multicentre randomised trial. Lancet 365:663-670

9. Shankaran S, Laptook AR, Ehrenkranz RA, Tyson JE, McDonald SA, Donovan EF, Fanaroff AA, Poole WK, Wright LL, Higgins RD, Finer NN, Carlo WA, Duara S, Oh W, Cotten CM, Stevenson DK, Stoll BJ, Lemons JA, Guillet R, Jobe AH 2005 Whole-body hypothermia for neonates with hypoxic-ischemic encephalopathy. N Engl J Med 353:1574-1584

10. Eicher DJ, Wagner CL, Katikaneni LP, Hulsey TC, Bass WT, Kaufman DA, Horgan MJ, Languani S, Bhatia JJ, Givelichian LM, Sankaran K, Yager JY 2005 Moderate hypothermia in neonatal encephalopathy: safety outcomes. Pediatr Neurol 32:18-24

11. Schulzke SM, Rao S, Patole SK 2007 A systematic review of cooling for neuroprotection in neonates with hypoxic ischemic encephalopathy-are we there yet? BMC Pediatr 7:30

12. Lorek A, Takei Y, Cady EB, Wyatt JS, Penrice J, Edwards AD, Peebles D, Wylezinska M, Owen-Reece H, Kirkbride V, Cooper RF, Alldridge RF, Roth SC, Brown G, Delpy DT, Reynolds EO 1994 Delayed (“secondary”) cerebral energy failure after acute hypoxia-ischemia in the newborn piglet: continuous 48-hour studies by phosphorus magnetic resonance spectroscopy. Pediatr Res 36:699706

13. Thoresen M, Haaland K, Loberg EM, Whitelaw A, Apricena F, Hanko E, Steen PA 1996 A piglet survival model of posthypoxic encephalopathy. Pediatr Res 40:738748

14. Haaland K, Loberg EM, Steen PA, Thoresen M 1997 Posthypoxic hypothermia in newborn piglets. Pediatr Res 41:505-512

15. Satas S, Loberg EM, Porter H, Whitelaw A, Steen PA, Thoresen M 2003 Effect of global hypoxia-ischaemia followed by $24 \mathrm{~h}$ of mild hypothermia on organ pathology and biochemistry in a newborn pig survival model. Biol Neonate 83:146-156

16. Gressens P, Dingley J, Plaisant F, Porter H, Schwendimann L, Verney C, Tooley J, Thoresen M 2008 Analysis of neuronal, glial, endothelial, axonal and apoptotic markers following moderate therapeutic hypothermia and anesthesia in the developing piglet brain. Brain Pathol 18:10-20

17. Thoresen M, Haaland K, Steen PA, Thoresen M, Haaland K, Steen PA 1994 Cerebral doppler and misrepresentation of flow changes. Arch Dis Child 71:F103-F106

18. Schubert A, Schubert A 1995 Side effects of mild hypothermia. J Neurosurg Anesthesiol 7:139-147

19. Amess PN, Penrice J, Howard S, Thoresen M, Edwards AD, Cady EB, Wyatt JS, Sams V 1998 Organ pathology following mild hypothermia used as neural rescue therapy in newborn piglets. Biol Neonate 73:40-46

20. Bernhard WF, Mc MJ, Curtis GW 1955 Feasibility of partial hepatic resection under hypothermia. N Engl J Med 253:159-164

21. Qing M, Nimmesgern A, Heinrich PC, Schumacher K, Vazquez-Jimenez JF, Hess J, von Bernuth G, Seghaye MC 2003 Intrahepatic synthesis of tumor necrosis factoralpha related to cardiac surgery is inhibited by interleukin-10 via the Janus kinase (Jak)/signal transducers and activator of transcription (STAT) pathway. Crit Care Med 31:2769-2775

22. deSa DJ 1995 Pulmonary complications of assisted ventilation. In: deSa DJ (ed) Pathology of Neonatal Intensive Care. Chapman \& Hall, London, pp 28-47

23. Cohen IT, Nelson SD, Moxley RA, Hirsh MP, Counihan TC, Martin RF 1991 Necrotizing enterocolitis in a neonatal piglet model. J Pediatr Surg 26:598-601

24. Haaland K, Loberg EM, Steen PA, Satas S, Thoresen M 1997 The effect of mild post-hypoxic hypothermia on organ pathology in a piglet survival model of global hypoxia. Prenat Neonatal Med 2:329-337

25. Frink M, Pape HC, van Griensven M, Krettek C, Chaudry IH, Hildebrand F 2007 Influence of sex and age on mods and cytokines after multiple injuries. Shock 27:151-156

26. Jensen A, Garnier Y, Berger R 1999 Dynamics of fetal circulatory responses to hypoxia and asphyxia. Eur J Obstet Gynecol Reprod Biol 84:155-172

27. Johnston MV, Hagberg H 2007 Sex and the pathogenesis of cerebral palsy. Dev Med Child Neurol 49:74-78

28. Yoneda S, Ibara S, Kobayashi K, Kato E, Maruyama Y, Maruyama H, Sumida Y, Sunami R, Sakai M, Ikenoue T, Saito S 2005 Low adjusted serum ionized calcium concentration shortly after birth predicts poor outcome in neonatal hypoxic-ischemic encephalopathy. J Obstet Gynaecol Res 31:57-64

29. Bickler PE, Hansen BM 1994 Causes of calcium accumulation in rat cortical brain slices during hypoxia and ischemia: role of ion channels and membrane damage. Brain Res 665:269-276

30. Johnston MV 1993 Cellular alterations associated with perinatal asphyxia. Clin Invest Med 16:122-132

31. Ilves P, Blennow M, Kutt E, Magi ML, Kudrjavtseva G, Lagercrantz H, Talvik T 1996 Concentrations of magnesium and ionized calcium in umbilical cord blood in distressed term newborn infants with hypoxic-ischemic encephalopathy. Acta Paediatr $85: 1348-1350$ 